\title{
Knee and Shoulder Arthritis Revealing Tabetic Arthropathy
}

\author{
B. Bannar ${ }^{*}$, M. Ouali. Idrissi, F. Jaafari, B. Boutakioute, N. Cherif Idrissi El Ganouni
}

Radiology Department, AR-RAZI Hospital, Mohamed VI Teaching Hospital, Cadi Ayyad University, Marrakesh, Morocco

DOI: $10.36347 /$ sjmcr.2021.v09i04.016

| Received: 02.03.2021 | Accepted: 22.03.2021 | Published: 22.04.2021

*Corresponding author: B Bannar

\section{Abstract}

The tabetic arthropathy is a destructive disease secondary to neurogenic infection tréponème. It has become exceptional with early treatment of syphilis [1]. A retrospective study of three cases, collected from the Arrazi hospital radiology department. All our patients consulted for joint deformity and instability. We reviewed the records of the osteoarticular and neurological clinical examination, as well as the radiological and biological examination; the 3 patients (men and 2 women) are treated on average for 50 years. A history syphilitic chancre is found in two cases. Neurological examination notes a patellar shock and osteo articular deformation, Joint involvement affects the knees in 2 cases and the shoulder in one case, TPHA and VDRL are positive in the blood in all patients and also in the cerebrospinal fluid. The radiological assessment shows a destruction and deformation osteoarticular in all cases. Treatment is medical with penicillin and orthopedic with orthosis. Tabetic arthropathy, an exceptional affection, is one of the complications of the syphilis its prevention relies on the treatment of the syphilis at an early stage, before the onset of the articular and neurologic forms, the management of which remains very difficult [2].

Key words: Tabetic arthropathy,syphilis, imagining.

Copyright $($ C) 2021 The Author(s): This is an open-access article distributed under the terms of the Creative Commons Attribution 4.0 International License (CC BY-NC 4.0) which permits unrestricted use, distribution, and reproduction in any medium for non-commercial use provided the original author and source are credited.

\section{INTRODUCTION}

Tabetic arthropathy, an exceptional affection, is one of the complications of the tabes dorsalis. Its prevention relies on the treatment of the syphilis at an early stage, before the onset of the articular and neurologic forms, the management of which remains very difficult [2].

\section{ResUlts}

A retrospective study of the files of three patients, collected over a period of 2 years at the radiology department of the CHU Mohammed VI in Marrakech. Our series contains 2 womens and men with an average age of 50 years:

First case: 39-year-old woman, with a history of syphilitic chancre and amputation of the right lower limb, who presented to the emergency room for swelling of the right shoulder with functional impotence in an apyretic context.

Our patient undergoes a standard X-ray supplemented by a CT scan of the right shoulder objectifying the following anomalies:

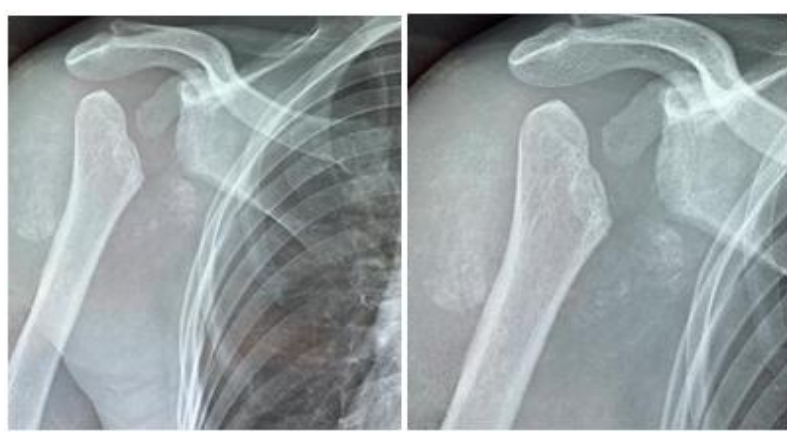

Fig-1: X-ray Important destruction of the articular surfaces of right shoulder

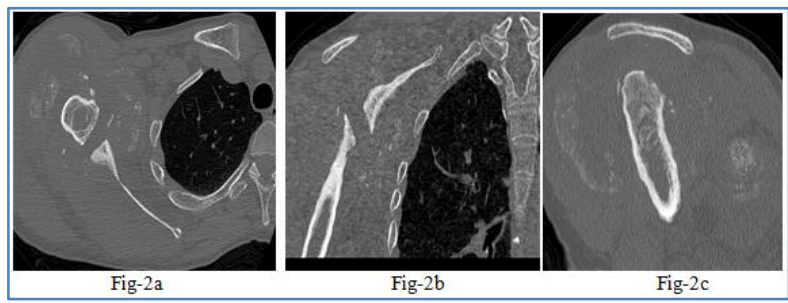

Fig-2: Bone window image of a CT scan of right shoulder in axial (Fig.2a),coronal(Fig.2b) and sagittal (Fig.2c) sections. 


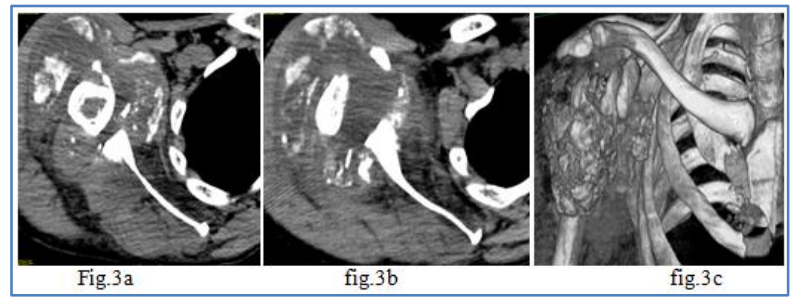

Fig-3: Soft tissue (fig.3a and fig.3b) and 3D window image (fig.3c) of $\mathrm{Ct}$ scan of right soulder.

Fig.2 and fig.3: Important destruction of the articular surfaces (cephalic parts of the humerus and the glenoid cavity) with detachement of bone fragments in the periarticular of the right shoulder,associated with calcifications of the soft parts and Moderate intra articular effusion.

The second case is about a 60-year-old woman with a history of syphilitic chancre, who presents for a swelling of the knee, The osteo-articular examination shows an articular deformation and a patellar shock, the diagnosis was retained in view of the positivity of the syphilitic serology TPHA and VDRL in the blood and cerebrospinal fluid (CSF). The patient benefited from a radiological assessment which objectified: On the radiological assessment (standard radiographs, CT and MRI) showing.

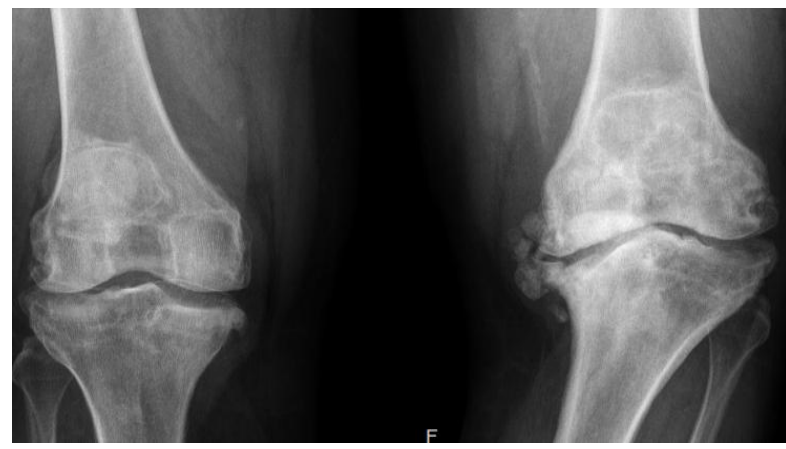

Fig-4: x-ray of both knees: joint damage affects the knees

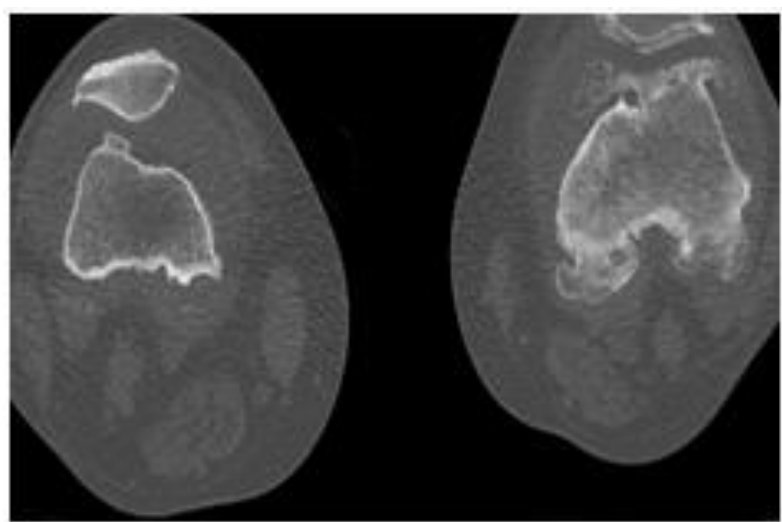

Fig-5: CT scan of both knees deformation of the left femoro tibial articular surface and detachment of bone fragments in the periarticular
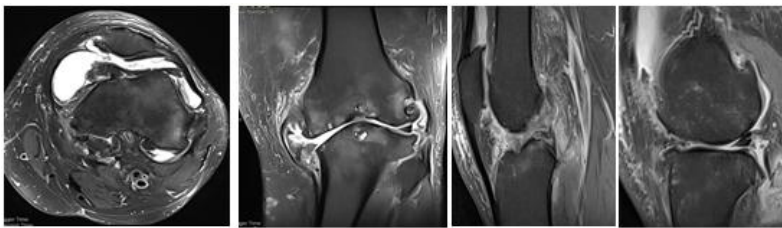

Fig-6: Magnetic resonance imaging showing DP FS axial, coronal and sagittal sections

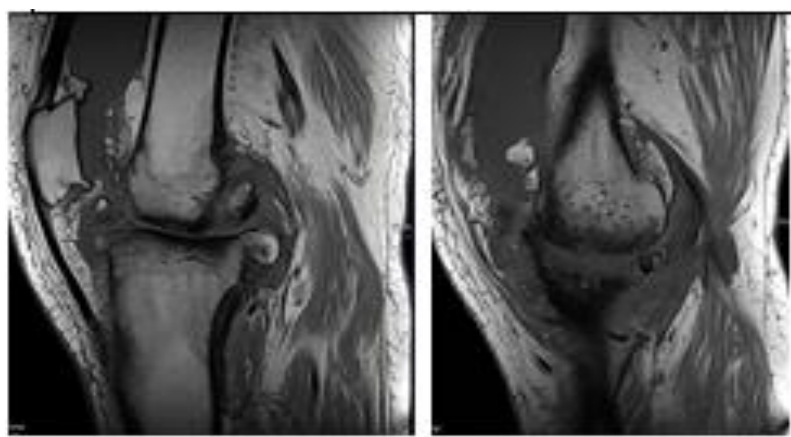

Fig-7a: Magnetic resonance imaging showing T1-weighte sagittal section

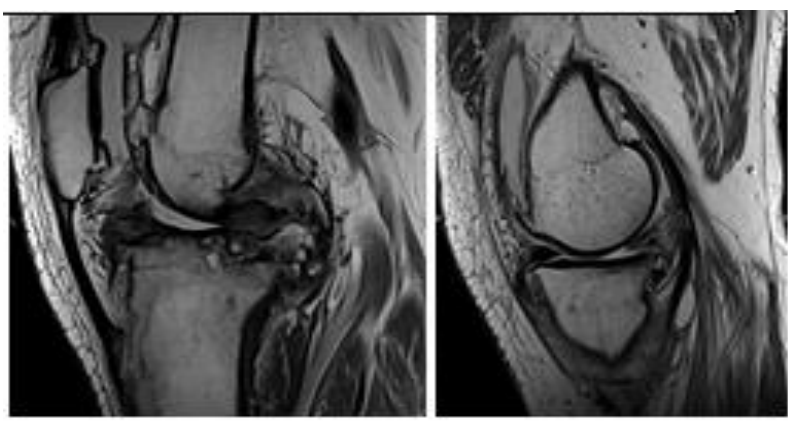

Fig-7b: Magnetic resonance imaging showing T2-weighted sagittal section

The MRI of 60 ans year old man followed for tabetic arthropathy,objective the Bilatéral osteo articular destruction of the knees associetes with intra and peri articular foreign bodies and moderate effusion.

The last case is about a 51 year old woman with no pathological history, who consults for a swelling of the left knee in a context of deterioration of the general condition, with serology TPHA and VDRL positive. Our patient undergoes a MRI which shows

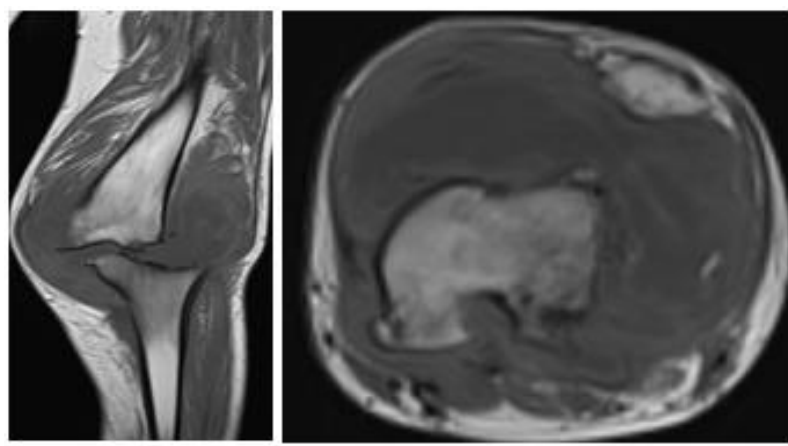

Fig-8a: Magnetic resonance imaging showing T1-weighted axial and sagittal section 


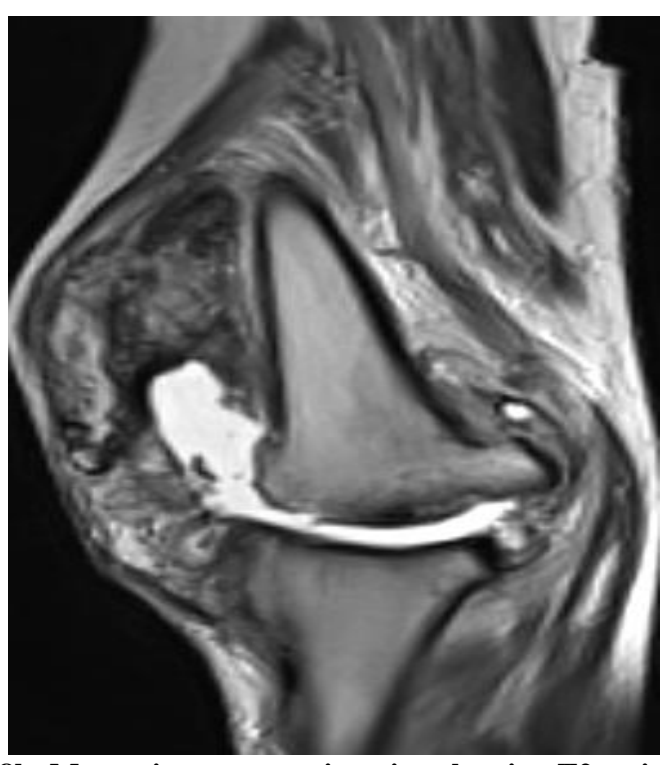

Fig-8b: Magnetic resonance imaging showing T2-weighted axial section

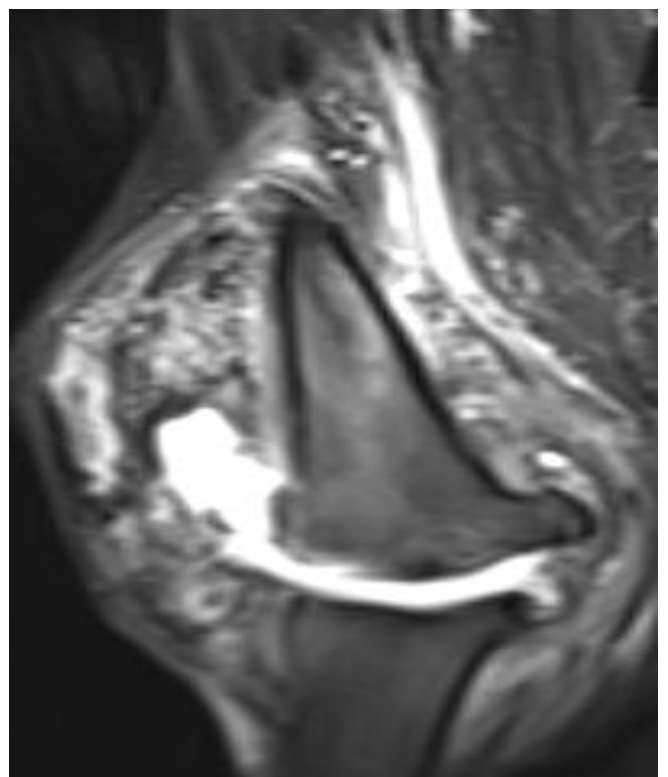

Fig-8c: Magnetic resonance imaging showing DP FS sagittal section

Fig-8a, 8b, 8c: The MRI showing: a 51-yearold woman, swelling of the left knee with no inflammatory signs. Bone and cartilage destruction of the articular surfaces of the left knee associated with synovial hypertrophy.

\section{DISCUSSION}

Tabetic arthropathy is estimated that worldwide, 12 million people are infected with the spirochete $\mathrm{T}$. pallidum each year, resulting in an incidence of 200 cases of primary syphilis per 100,000 individuals [1].

In Morocco, the real incidence of the disease is unknown. However, in 1995, the prevalence of syphilis was evaluated in blood donors to be $1.4 \%$ [2].
TA occurs at the late stages of the disease, usually 20 to 30 years after primary syphilis. The articular involvement may concern every joint, but more particularly concerns those of the lower limbs: knees, hips, feet, and the lumbar spine. The involvement of the shoulder is rare in this condition (syringomyelia-like form) [3].

All joints can be affected with a predominance net for the lower limb (knee, foot) and the lumbar spine Radiological examinations showed joint destruction, with images of arthrosis reconstruction and rearrangements in the four observations, associated with joint dislocation [2].

Conventional radiographs of early tabetic arthropathy show thinning of the articular cartilage and cyst formation. These abnormalities progress to complete disorganization of the joint[4].

Pathologic, mostly transverse, periarticular fractures and subluxations of the articular surfaces are common. Hypertrophic, atrophic, and mixed patterns are depicted radiographically. The hypertrophic joint is manifested as joint destruction and fragmentation, osseous sclerosis, and bony proliferation [4].

There is bony and cartilaginous debris in the joint cavity, new bone formation in the synovial membrane and subsynovial tissues, and formation of enormous-sized and Bizarre-shaped osteophytes.

The atrophic type of tabetic arthropathy has an appearance of osseous reabsorption and is more common in nonYweight-bearing joints[4].

Abnormal findings on radiographs include subchondral sclerosis, osteophytosis, subluxation, andsoft tissue swelling. Long-standing neuroarthropathy is characterized by a disorganization of joints. These radiographic features are pathognomonic, and no further imaging is necessary [5]. However, early changes may resemble infection, osteonecrosis, calcium pyrophosphate dihydrate crystal deposition disease, psoriatic arthritis, osteoarthritis, and osteolysis with detritic synovitis [6].

MRI and radionuclide scanning can help in differential diagnoses [7]. Penicillin remains the drug of choice for all forms of neurosyphilis and for TA. It was used in all of our cases. The aim of the use of Penicillin is to sterilize the infectious lesions and to stabilize the joint damage. Local treatment of joints remains poor [3].

Joint lavage, local corticotherapy, or synoviorthesis may be used in important effusions. Palliative reduction of instability by immobilization and the cessation of weight bearing and/or diverse ways of contention remain, however, of utmost importance 
because of the role of traumas, even minor, in the worsening of the impairment. Surgery may be discussed in the most impaired forms of TA (arthrodesis). Attempted joint prostheses have often resulted in the loosening of those prostheses [8]. However, fair results have been reported in some cases [9].

\section{CONCLUSION}

All joints can be affected, with dominance of the foot and knee jointsand the thoracolumbar spine. The radiologic appearance is a char-acteristic of the disease, and the positive syphilitic serology in joint fluid, blood or CSF is essential to confirm the diagnosis [1]. Man-agement of tabetic arthropathy remains difficult.

\section{REFERENCES}

1. Imane Rekkab, Ahlam Belkhou, Imane El Bouchti, Selma El Hassani Arthrotabès : à propos de 9 cas. Tabetic arthropathy : a report of 9 cases. Rev Mar Rhum. 2013; 23: 43-6

2. Zouhair K, Akhdari N, El Ouazzani T, Lazrak S, Lakhdar H. Arthropathie tabétique:«une maladie oubliée». InAnnales de dermatologie et de vénéréologie 2004 Aug 1 (Vol. 131, No. 8-9, pp. 787-789). Elsevier Masson.
3. Allali F, Rahmouni R, Hajjaj-Hassouni N. Tabetic arthropathy. A report of 43 cases. Clinical rheumatology. 2006 Nov;25(6):858-60.

4. Schotanus MD, Desire'e MJ, Dorleijn MD, Allard JF Hosman MD PhD, Ralph MHG Huits, MDP Peter P. Koopmans MD, PhDP and Jochem MD. Galama, MD, PhDp A Patient With Multifocal Tabetic Arthropathy: A Case Report and Review of Literature the American Sexually Transmitted Diseases Association. Number 3, March 2013

5. Jones EA, Manaster BJ, May DA, Disler DG. Neuropathic osteoarthropathy: diagnostic dilemmas and differential diagnosis. Radiographics. 2000 Oct;20(suppl_1):S279-93.

6. P Martinet $1 \mathrm{P}$ M'Bappé, C Lebreton, $\mathrm{O}$ Heinzleff, $M \quad$ Sibony, $C \quad$ Papeix, T Judet,Neuropathic Arthropathy: A Forgotten Diagnosis? Two Recent Cases Involving the Hip Rev Rhum Engl Ed.1999 May;66(5):284-7.

7. YH Park 1, JA Taylor, S M Szollar, D Resnick Imaging Findings in Spinal Neuroarthropathy Spine (Phila Pa 1976). 1994 Jul 1;19(13):1499-504.

8. G Gualtieri 1, A Sudanese, A Toni, A Giunti Loosening of a Hip Prosthesis in a Patient Affected With Tabetic Disease Chir Organi Mov. Jan-Mar. 1991;76(1):83-5.

9. Yoshino S, Fujimori J, Kajino A, Kiowa M, Uchida $\mathrm{S}$ Total knee arthroplasty in Charcot's joint. The Journal of Arthroplasty. 01 Jun 1993, 8(3):335-340. 